\title{
The Hierarchical Structure of Ecosystems: Connections to Evolution
}

\author{
William Miller III
}

Published online: 20 November 2007

(C) Springer Science + Business Media, LLC 2007

\begin{abstract}
Ecologic systems, which are involved mainly in the processing of energy and materials, are actually nested one inside another - they are simultaneously parts and wholes. This fundamental hierarchical organization is easy to detect in nature but has been undervalued by ecologists as a source of new insights about the structure and development of ecosystems and as a means of understanding the crucial connections between ecologic processes and large-scale evolutionary patterns. These ecologic systems include individual organisms bundled into local populations, populations as functional components of local communities or ecosystems, local systems making up the working parts of larger regional ecosystems, and so on, right up to the entire biosphere. Systems at any level of organization can be described and interpreted based on aspects of scale (size, duration, and "membership" in more inclusive entities), integration (all the vital connections both at a particular focal level and across levels of hierarchical organization), spatiotemporal continuity (the "life history" of each system), and boundaries (either membranes, skins, or some other kind of border criterion). Considering hierarchical organization as a general feature of ecologic systems could reinvigorate theoretical ecology, provide a realistic scaling framework for paleoecologic studies, and - most importantly - forge new and productive connections between ecology and evolutionary theory.
\end{abstract}

Keywords Hierarchy theory · Neoecology · Paleoecology · Ecologic theory - Organization and development .

Evolution $\cdot$ Scientific realism

\footnotetext{
W. Miller III $(\bowtie)$

Geology Department, Humboldt State University,

1 Harpst Street, Arcata, CA 95521, USA

e-mail:wm1@humboldt.edu
}

\section{Introduction}

This essay is about the organization of ecologic systems of all kinds - from individual organisms and their functional parts up to regional ecosystems and on to the entire biosphere. The approach will involve characterization of the basic properties of such systems. I will also explore two rather serious misconceptions in evolutionary biology, related to hierarchical organization. One of these is the notion that everything that is interesting or significant about ecology can be explained in terms of (or reduced to) processes associated with individual organisms, or at most, populations of such organisms. The other misconception is embodied in the phrase "evolution takes place on an ecologic stage." Both of these views have not only resulted in a general underestimation of the complexity of the living world, but also have led to grossly inaccurate paleoecologic reconstructions, have made it seem that neoecology was running out of steam, and - I think most seriously - have limited the growth and expansion of evolutionary theory.

Serious discussion of these issues began two decades ago with a burst of activity in hierarchy theory applied to biology. A series of fascinating publications in the 1980s summarized the characteristics of hierarchical systems, explored the ontologic status of entities or systems at various levels within both genealogic (evolutionary) and economic (ecologic) hierarchies, and began to focus on the connections between the behavior of ecologic systems of varied scale and evolutionary processes and patterns (Eldredge and Salthe 1984; Salthe 1985; Eldredge 1985; Allen and Starr 1982). Later publications elaborated on these same themes (O'Neill et al. 1986; Eldredge 1989, 1990; Allen and Hoekstra 1992; Ahl and Allen 1996). Any serious student would want to examine these contributions firsthand to get an idea of the nature of the debate about the 
reality of hierarchical entities and the utility of a hierarchical approach to ecologic and evolutionary theory. In my view, the most reliable and useful of these guides to hierarchy theory are those that accept hierarchical organization as a real feature of living systems in general, not merely an empirical (and potentially disposable) position, heuristic device, or convenient taxonomic system. As I show below, biologic hierarchies are obviously real, but their importance has not been much appreciated.

\section{Hierarchical Properties of Ecologic Systems}

Accepting a hierarchical perspective involves neither the abandonment of orthodox biologic orientations nor much of a stretch of a person's imagination. Consider a small stream together with its surrounding countryside (Figs. 1 and 2). Keep in mind that the properties of the systems I am about to describe have to do primarily with "making a living" the processing of energy and materials - or the economy of nature as Charles Darwin put it (Darwin 1859).

At any particular time, the channel of the stream might consist of quiet-water pools separated by rocky, high- energy zones called riffles. Collection of aquatic organisms from these two different fluvial settings would reveal that the two different habitats harbor several different species, although some kinds of organisms would probably live in both places. Within any of these pools or riffles, one would notice immediately that some species are exceedingly abundant and easy to collect, while others might be rare and would require a bit of effort to find. With respect to one of the numerically dominant species, we could collect enough specimens to reveal growth or developmental stages of that particular kind of organism, or we could spend time observing the behavior of living individuals belonging to that species. So far, we would have described or delineated, in the order described, local ecosystems of the stream, populations within each of these local ecosystems (known in the hierarchy literature as avatars), and individual organisms.

Now, look at the same picture "in the other direction." The local ecosystems within the channel of the stream certainly have more properties in common than they do with local ecosystems of the adjacent floodplain. Such closely connected local systems are termed biotope systems, the most obvious linkages in this case involving down-
Fig. 1 A hypothetical stream and surrounding countryside. Local ecosystems coincide with: $A$ upland plateau; $B$ talus-covered slope and beach; $C$ small, recent landslide; $D$ riffle zones in the stream channel; $E$ quiet water pools; $F$ sandy point bar; $G$ oakhickory forest; $H$ pine forest; and $I$ pond/freshwater marsh on the floodplain. Diagram at bottom shows the hierarchical position of any of these local ecosystems

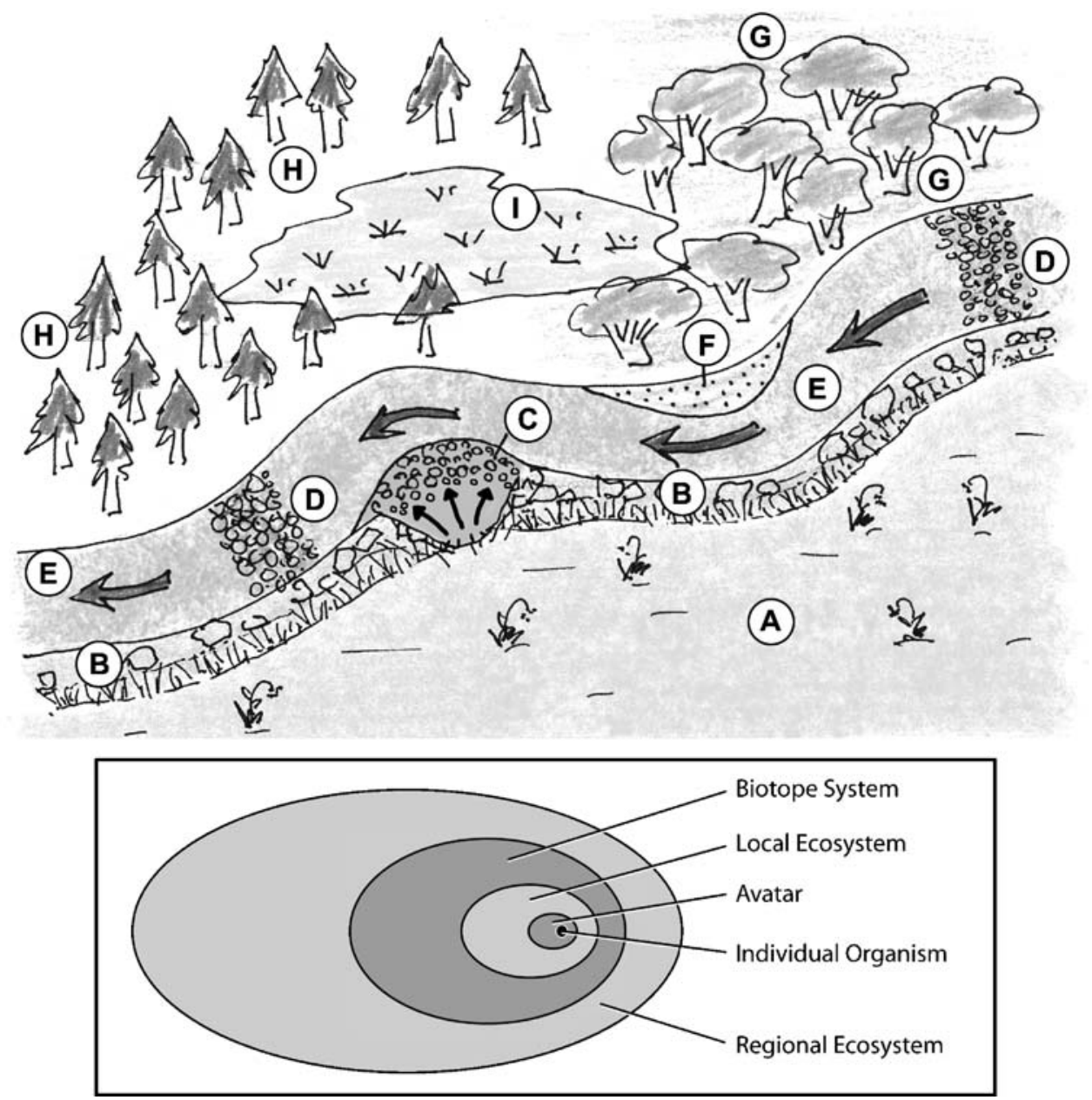




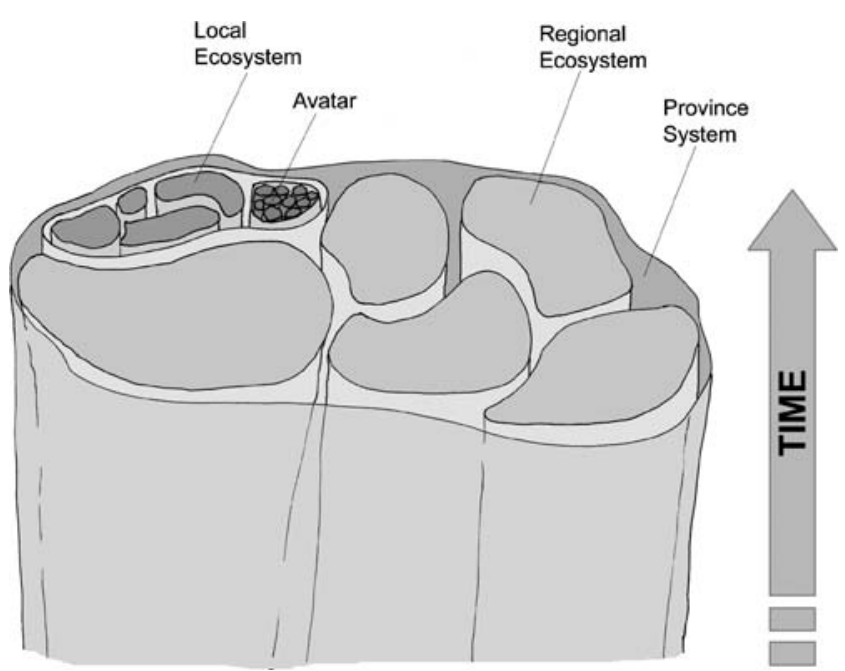

Fig. 2 The same ecologic systems depicted in Fig. 1, extended through time

stream drift of organisms during regular flow stages and especially during intervals of high discharge (floods). Such closely connected local systems also share energy and materials, such as organisms normally residing in upstream locations ending up as prey for downstream predators, or simply as downstream transport of organic particles that could be exploited by detritus feeders. The bars and beaches might also be included in this biotope if their resident organisms have similar close connections to the channel systems. But what about local ecosystems of the adjacent floodplain? Could they be construed as connected in some way to the channel ecosystems, thereby forming a much larger regional ecosystem? Ponds and other low-lying areas would receive colonists from the riffle and pool ecosystems during major floods; organic material that accumulated in such settings might be flushed into the channel during the same events. Riparian forests could contribute to the habitat structure of channels as trunks and crowns of trees that have fallen into the stream; floodplain animals could depend on fluvial invertebrates as a food resource.

It is not hard at all to picture ecologic organization at varied scales in this way and to see that ecologic systems are simultaneously parts and wholes - which is what they would have to be to qualify as real hierarchical entities (Salthe 1985). It can also be shown that all of these systems big and small - interact with each other, have boundaries of some sort, and go through something akin to "life cycles."

\section{Some Formalities: The Properties of Hierarchical Entities}

Niles Eldredge and Stan Salthe did more than anyone else to outline the fundamental properties of biologic hierarchies and the characteristics of hierarchical entities (Eldredge and
Salthe 1984; Salthe 1985, 1993; Eldredge 1985). These authors approached metasystems like the hypothetical channel-flood plain example described above as real things in the world, with each level of organization featuring unique properties (Fig. 3). In doing this, they have provided one of the clearest windows on hierarchy theory as it applies to organization of ecologic systems. The following is based on their work, and on my more recent papers (Miller 1990, 1991, 1996).

Scale Probably the most obvious property of hierarchical entities of all kinds has to do with their relative sizes and related process rates. Large, inclusive ecologic systems cover larger areas and usually "work slower" and last longer than the smaller, embedded systems. Although it may seem unnecessary to say so, any consideration of scale must also take into account membership: sometimes component systems have exactly the same geographic extent as the enclosing system (some avatars have the same distribution pattern as the encompassing local ecosystem), but their status as components or working parts places them at a lower hierarchical level. In addition, component systems are characterized by faster rate constants compared to enclosing systems (an avatar of salamanders may wax and wane in terms of abundance of individuals over the course of decades, but each individual salamander completes its life cycle in just 2 years and physiologic processes within salamander bodies take place on a scale of minutes to hours).

Integration Ecologists have devoted much effort to the study of interactions, from idealized pair-wise linkages (such as competitive interaction between two different avatars in the same local ecosystem) to complex networks

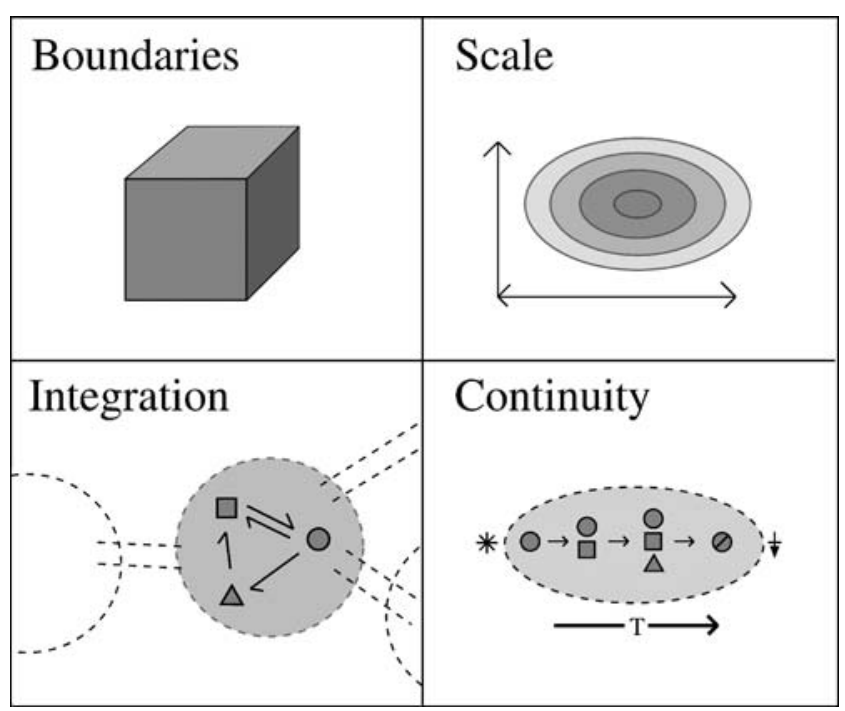

Fig. 3 Fundamental properties of hierarchical entities of all kinds 
that attempt to portray all of the components and connections in a community or local ecosystem. This "internal wiring" gives local ecosystems the appearance of being things separate from other things at the same scale and at the same time (Salthe 1985). Ecologic interactions involve the transfer of energy and materials - the fundamental currencies of ecologic systems of all types and scales.

It is important to realize that interaction, or networking, not only takes place between entities but also across hierarchical levels. For example, an avatar of freshwater snails in our hypothetical example would not only derive its essential ecologic properties from interactions with the other co-occurring avatars in a stream pool, but also from the interaction of its internal working parts (the behaviors of individual snails) and from its position in the food web of the local environment (an organizational property of the local ecosystem). Hierarchy theorists have formalized this complex network of interactions involving entities that are simultaneously parts and wholes as the "triadic system of causation" (Salthe 1985; Miller 1990): the avatar of snails is the focal level of interest in this case, the component organisms present initiating conditions (relating to possibilities), and the encompassing local ecosystem presents boundary conditions (relating to constraints). In other words, understanding the organization and development of avatars must include an account of one-on-one interaction with other avatars, plus interaction between the avatar level and the level of individuals on the one hand and interaction of the avatar with the encompassing system on the other. Stable networks should produce stable ecologic systems. For example, a long-lasting metapopulation structure of freshwater snails in a large fluvial system probably supports regional ecosystem stability over long intervals of time.

Spatiotemporal Continuity Genealogic entities have distinct beginnings, unique histories, and eventual terminations. For example, species have a kind of birth (speciation); a life history involving geographic deployment and fate of demes, ecologic involvements, and phylogenetic potential; and an eventual death (species-lineage extinction). However, can we say that ecologic systems have the same kind of spatiotemporal extent (Fig. 2)? Many ecologists would simply preempt the discussion here by saying "no"claiming that most are happenstance, fluctuating assemblies of organisms thrown together by random processes. I think there is more to it than this. Picture again the stream and flood plain example (Fig. 1). Imagine a large landslide derived from a rocky cliff bordering one side of the stream and covering part of the valley floor. An event such as this could dam the channel and produce a shallow lake, causing inundation of the flood plain and conversion of the lotic (flowing water) environment of the channel to a lentic (standing water) environment. Many of the established local ecosystems would be wiped out by this catastrophe-their "lives" would end as the component avatars underwent local extinction or individual organisms migrated to more favorable habitats. Perhaps some species from the pools and pond environments would flourish in the new regime, together with recruits from other areas that prefer shallow lacustrine settings. In short, the previous regional ecosystem would be replaced by a new one having different ecologic properties (in terms of species composition, relative abundances, and organization of food webs). The event producing ecosystem replacement certainly has a random quality to it, but the organization and function of the new system would not look all that random.

This new regional system might persist for centuries, until the landslide deposits are washed away in a major flooding event. In the meantime, the lentic system would have experienced disturbances and recoveries at varied scales, caused by droughts that lowered water level, intervals of low $\mathrm{O}_{2}$, elevated turbidity, or events involving short-lived invasion of predators - all of which would have caused ecologic properties to fluctuate but would not have resulted in regional system collapse. In this view, the regional system really has a life span (between establishment of the lake and its eventual disappearance) and a unique life history (related to primary organization of the component local ecosystems and to disturbances and recoveries affecting those component systems). When ecologists speak of disturbance regimes, succession, and replacement, or when they show that a community has a certain geographic extent on a base map, they are owning up to the fact - whether they realize it or not - that things like local and regional ecosystems actually have spatiotemporal continuity.

Boundaries Because local ecosystems may have gradational borders coinciding with gradual changes in physical and chemical factors of the environment (called ecoclines), instead of always having sharp borders defined by steep environmental gradients (ecotones), some ecologists have decided that local multispecies assemblies cannot be construed as entities that are anything like an individual organism. However, ecologic systems should be expected to have different kinds of boundaries, depending on the type and scale of the system, compared to more familiar individual organisms with their skins and membranes. In some cases, abrupt change in the features of the enclosing environment reveals (or coincides with) the borders of local and regional ecosystems. It might be more appropriate, however, to "map" such entities using a kind of circuit diagram, showing which subsystems are included and which are excluded from the dynamic structure of a system of interactors. It would not matter if the positions or intensities of boundaries changed during system development. They 
certainly do with organisms (think about the life cycle of a colonial animal, such as a coral, involving growth, morphologic change, and expansion on the seafloor). Moreover, we begin to lose concern for the "boundary problem" when we look at satellite images of North America or Europe, which reveal the extent of different types of forests and grasslands controlled largely by climate, geology, and evolutionary history of the plant groups - large, fairly long-lived systems apparently having geographic borders or transition zones coinciding with entity boundaries (some of which are produced by human activity).

In the hypothetical channel-flood plain regional system, a stroll through the woods to the edge of the steam would require either a change of route or else a splash in the water (detection of an abrupt system boundary we could easily plot on a base map). Noticing the more subtle differences in species composition and relative abundance within the forested parts of the flood plain could reveal similar, if less dramatic, transitions corresponding to much more gradual changes in soil type, moisture, topography and disturbance regime. In all these cases, we are confirming the boundary criterion.

\section{Some Consequences of Ignoring Hierarchical Organization}

Attempting to practice ecology admitting only individuals and populations as units of description and interpretation has turned out to be a rather serious form of scientific tunnel vision. For example, many community ecologists have always doubted the existence of assembly rules or emergent properties of various kinds of multispecies aggregates. Behavior of individual organisms and population-level processes explained everything. (It is noteworthy that the systems ecologists never followed this route; but it is curious that they never really explored the ontologic properties of the large dynamic systems they analyzed.) In the late twentieth century, as ecology became preoccupied with mathematical modeling, some practitioners began to think their discipline had progressed (theoretically, conceptually) about as far as it could go. Reinvigoration of ecology came as workers "scaled up" their studies and started to think seriously about the consequences of historic legacy and contingency. New approaches included work on metapopulation networks, "metacommunities" and regional trophic webs, large-scale distribution patterns of species, and the long-term development of landscapes, often pursued in the cause of conservation ecology (Likens 1989; Delcourt and Delcourt 1991; Gilpin and Hanski 1991; Brown 1995; Gaston and Blackburn 2000; Polis et al. 2004; Holyoak et al. 2005). Ecologists were embracing a hierarchical perspective, but without seriously considering the ontologic reality of the nested systems they had encountered - and therefore never suspected that important processes and patterns unique to different levels of organization might have been overlooked or that crucial connections to evolutionary theory might have been missed.

A consideration of larger, more inclusive units of organization is clearly needed in some cases. For example, how can we talk about the global carbon cycle and climate change only in terms of individuals and populations? How can we determine the processes that result in the stable species-lineages of punctuated equilibria without considering the properties of the enclosing regional or provincial ecosystems, which sometimes also appear to be stable over millions of years? What happens when climatic or geologic processes lead to reorganization or replacement of these regional systems, producing waves of abandonment, invasion, extinction, and especially speciation events? What are the major ecologic controls of species richness and development of clades over even longer time spans and over larger geographic areas? Reductionism does not serve us very well in these cases.

A related problem has affected the development of paleoecology. Beginning in the 1960s, many marine paleoecologists interpreted vertical sequences of fossil assemblages as examples of ecologic succession (initiation or reestablishment and maturation of local ecosystems controlled mostly by internal processes) - no matter how thick the associated stratigraphic succession, what type of paleoenvironmental context, or how drastic the changes in the composition of the fossil assemblages. This obviously was not right. It is now accepted that most of these purported cases of succession in the fossil record were really replacement sequences consisting of the remains of different local or regional ecosystems, paced by environmental fluctuations often caused by large-scale climatic and geologic processes (Miller 1986). Notwithstanding this fundamental scaling correction, many paleoecologists continue to refer to almost any sample of fossils - of almost any size - as a "community." Is it any wonder that much of the rich literature of paleoecology has been ignored by neoecologists?

\section{Rewards for Getting it Right}

It is an odd fact that ecology and evolutionary biology developed as essentially separate fields during most of the twentieth century. Other than the notion of adaptation (a term used in many ways, both as verb and noun-process and product), evolutionary theorists had little of substance to say about the connections between the economic (ecologic) and genealogic (evolutionary) realms of life. The most 
Fig. 4 Species-lineage extinctions and speciation events during a turnover pulse; invasions and abandonments would also occur. The varied patterns include: $A$ extinction of an abundant, ecologically dominant species; $B$ extinction of a moderately abundant species; $C$ rare species originating from an abundant ancestor; $D$ an abundant species that undergoes a reduction in abundance, but subsequently recovers; $E$ formerly abundant species reduced to rarity; $F$ a rare species that persists through the turnover pulse; $G$ a rare species that becomes abundant and ecologically dominant in the subsequent regime; $H$ an abundant species derived from a rare ancestral species; $I$ a rare species that vanishes early in the turnover pulse; and $J$ a rare species yielding many descendant species (based on Miller 2005, Fig. 1)

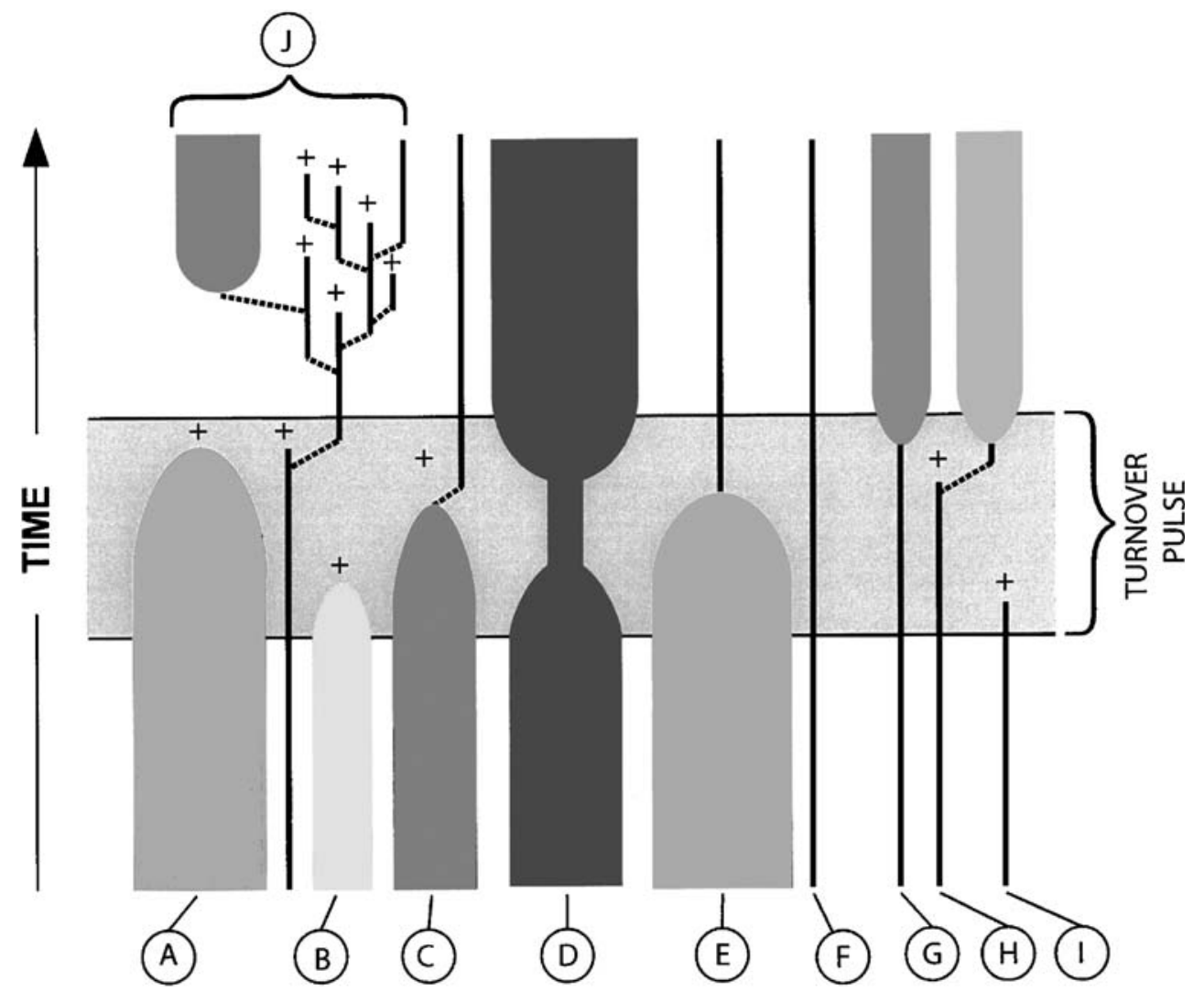

important property of life was the reproduction of fertile offspring, as well as the perfection and spread of such reproductive systems. Ecology was seen as mostly the backdrop to these most essential processes. Although a reunion of evolutionary biology and neoecology has been heralded in recent articles and books (reviewed in Johnson and Stinchcombe 2003), the most dramatic breakthroughs seem to be coming from reevaluation of the fossil record from a hierarchical perspective.

One of the surprises in the recent paleoecologic literature was a series of papers and an entire journal issue (Ivany and Schopf 1996) evaluating a pattern of apparent ecosystem stability lasting, in some cases, for millions of years, referred to as "coordinated stasis." It appears that large marine ecologic systems can be exceedingly durable, reminiscent of (and probably related to) the stable species lineages of punctuated equilibria. This pattern of paleoecologic stasis was detected in the "deep" fossil record, but is not in accordance with patterns of repeated reassortment of terrestrial species documented by ecologists over the last few tens-of-thousands of years, paced by late PleistoceneHolocene climate changes. The difference in perspective between neo- and paleoecology needs to be worked out, both here and with respect to other observations and conceptual issues. What we seem to be seeing in the fossil record, however, is a pattern of stability not associated with communities or local ecosystems but, rather, involving large, inclusive regional ecosystems. At this higher level of organization, we must look for novel processes that maintain composition and organization over times spans in the order of hundreds-of-thousands to millions of years (Miller 1996) _ opening nothing less than a new frontier for ecologic theory.

A related development has to do with regional extinctions and waves of more or less concurrent speciation events that mark the intervals of reorganization/replacement

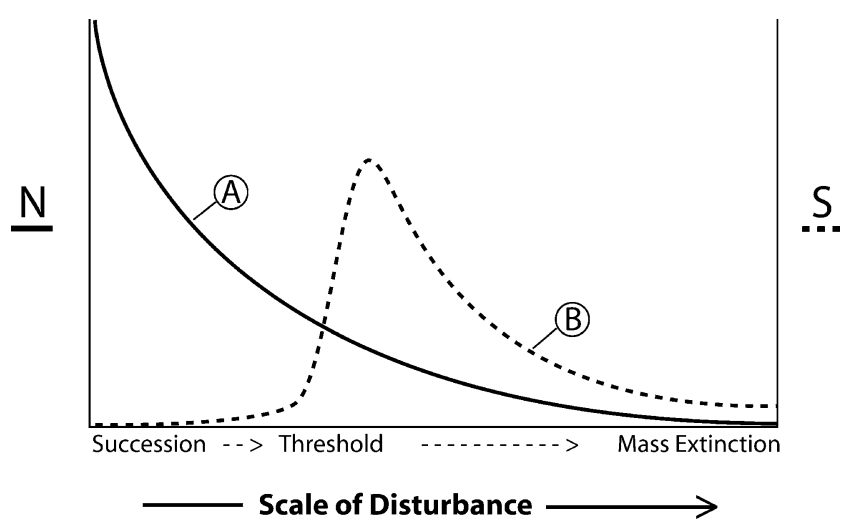

Fig. 5 The sloshing bucket model of evolution. $A$ represents the frequency of disturbances of different intensities and geographic scope through time, $N ; B$ represents the accumulation of adaptive speciation during the Phanerozoic, $S$. Note that, in this view, most speciation is associated with intermediate levels of disturbance, not with "background" processes or with global mass extinctions (Miller 2004, Fig. 1) 
of these same regional ecosystems (Figs. 4, 5, and 6). Elisabeth Vrba $(1980,1985,2005)$ was the first to draw attention to these events, referring to them as turnover pulses. Eldredge $(1999,2003)$ has built on this theme with his sloshing bucket model of evolution. In his broad view of evolutionary theory, the larger the environmental jolt, the bigger the evolutionary reaction, an inherently hierarchical approach. Small disturbances produce little in the way of phenotypic evolution, and global-scale mass extinctions are very rare-albeit associated with some of the grandest evolutionary transformations in the history of life on Earth.
However, the regional turnovers are both hundreds of times more frequent than mass extinction and represent the thresholds where invasions/abandonments and extinctions/ speciation events start to happen. In his thinking, nothing much happens in terms of adaptive evolution until the regional systems get into trouble - a connection between ecologic and evolutionary systems I call macroevolutionary consonance (Miller 2004). In other words, most of the species-level evolution during the Phanerozoic Eon (i.e., during the time when the fossil record has been rich enough to record these patterns) probably occurred at the interme-

Fig. 6 The ecologic structure of turnover pulses. a Reduction of an abundant, widespread species (a metapopulation consisting of sources and sink populations, 1 $5)$ to a few isolated remnants (68) - a situation likely to promote a bout of allopatric speciation (if the population remnants are not too small). b Simultaneous collapse of numerous local ecosystems (1) that were connected in various ways (2) to produce a regional network, resulting in a few disconnected remnants (3). c Turnover in terms of changes in relative abundance of the resident organisms $(a-j)$, with some rare species becoming abundant (1), prominent species reduced in abundance (2), and reduction or complete elimination of other species (3)

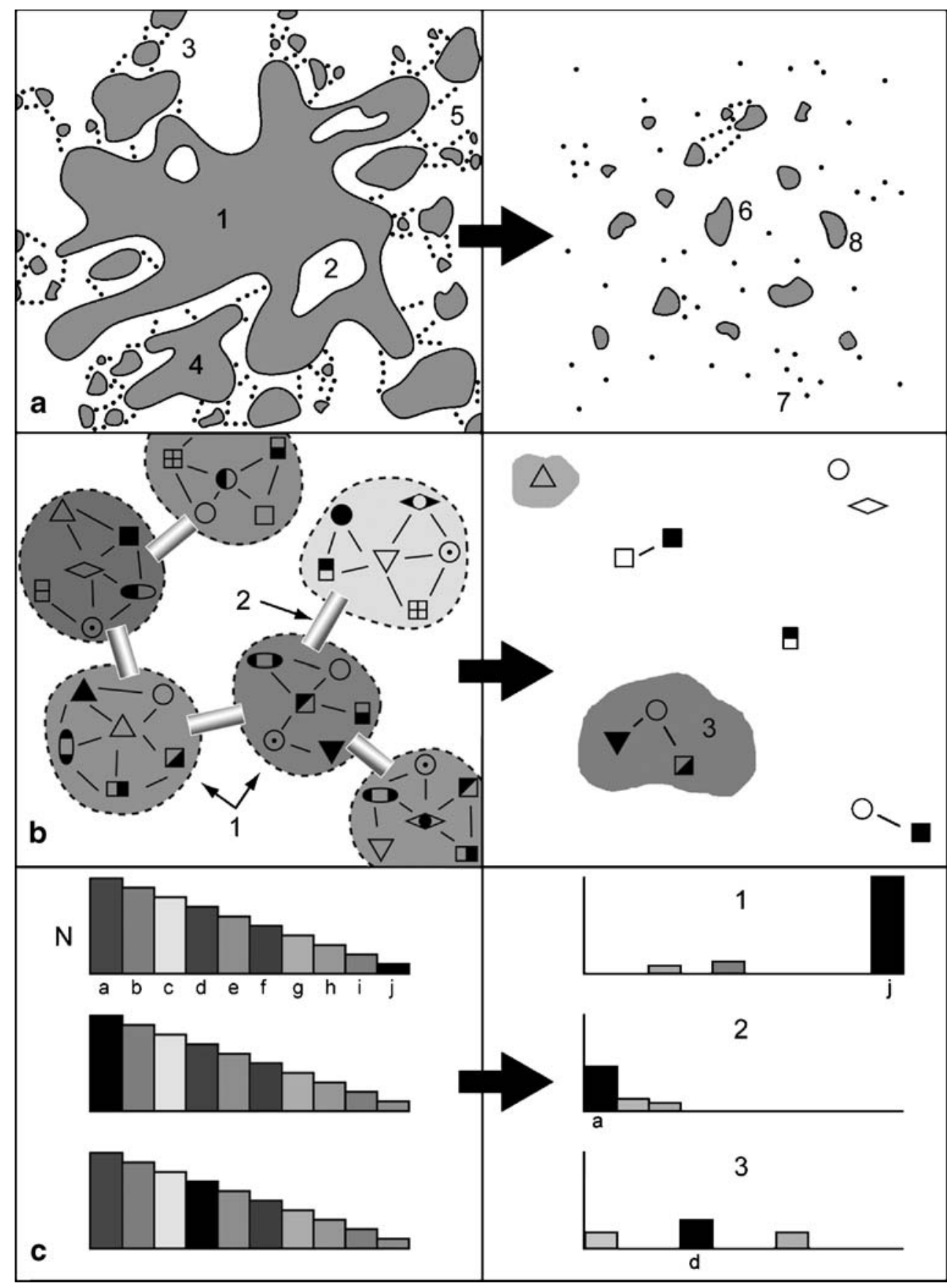


diate scale of the sloshing bucket (Fig. 5) - not during the longer "background" intervals or in the recovery phases following mass extinctions. This is an extremely interesting idea that needs more empirical work, but it would never have been conceived in the first place without the kind of hierarchical perspective I have described. I think these developments clearly demonstrate that evolution does not simply take place on an ecologic stage; evolutionary and ecologic processes are interconnected and interwoven at varied scales, often take place concurrently and in coordination, and simultaneously propel and constrain one another in ways we have barely imagined when it comes to turnovers, extinctions, and appearance of new species (Miller 2004).

\section{Conclusions: Why Hierarchies?}

What actually produces hierarchical organization in the first place? Nested dynamic systems are a real feature of life on Earth, but what produces this ubiquitous pattern of nestedness? The genealogic hierarchy can be viewed as the simple by-product of living systems making more of themselves and spreading to different geographic localities. The ecologic hierarchy arises from interacting aggregates of organisms occurring in more than one setting having at least slightly different resources, opportunities, and hazards. Fundamentally, hierarchies of living organisms and organism aggregates seem to be essentially about packing the maximum amount of complexity into the same container or package. There are principles of thermodynamics involving large, complex systems at work here that need elucidating. Salthe $(1985,1993)$ reviewed some of these issues.

As Eldredge noted in his book, Unfinished Synthesis (Eldredge 1985), "Hierarchies at first glance seem to make matters much more difficult, providing no help at all in managing complexity because they are themselves so complex. But hierarchies actually deal with complexity by teasing it apart; it is as if hierarchies are more honest in their simple recognition that a system is complex than is an approach that seeks unity in characterizing the system in simple terms - such as in description of evolution provided by later versions of the synthesis." Considering the hierarchical organization of evolutionary and ecologic systems increases the possibility of detecting and correctly interpreting more processes and patterns than a strictly reductionist program would allow.

The alert reader will have detected a vein of scientific realism running through all this (Blackburn 2005): not only does owning up to hierarchical organization of biologic systems enrich and extend my ability to generalize about how life works, I can also take that fateful stroll across a flood plain (as I pretended to do earlier in this essay) and personally encounter patent examples of these nested systems and experience at least some of their basic properties. We know what the possibilities are: the question becomes, how can we use this more inclusive view of life to expand and improve ecologic and evolutionary theory, to make instruction in evolutionary biology more comprehensive and realistic, and to forge new and mutually enriching connections to related disciplines?

Acknowledgements This essay is based on a presentation in the Hierarchy Symposium, held as part of the Genova Festival di Scienza, November 2006. I thank Niles Eldredge and Telmo Pievani for their invitation to participate, and the organizers for their generous support. Eldredge and Bud Rollins provided insightful reviews.

\section{References}

Ahl V, Allen TFH. Hierarchy theory: a vision, vocabulary, and epistemology. New York: Columbia University Press; 1996.

Allen TFH, Hoekstra TW. Toward a unified ecology. New York: Columbia University Press; 1992.

Allen TFH, Starr TB. Hierarchy: perspectives for ecological complexity. Chicago: University of Chicago Press; 1982.

Blackburn S. Truth: a guide. Oxford: Oxford University Press; 2005.

Brown JH. Macroecology. Chicago: University of Chicago Press; 1995.

Darwin C. On the origin of species. Facsimile of 1st ed. Harvard: Harvard University Press; 1859.

Delcourt HR, Delcourt PA. Quaternary ecology: a paleoecological perspective. London: Chapman and Hall; 1991.

Eldredge N. Unfinished synthesis: biological hierarchies and modern evolutionary thought. New York: Oxford University Press; 1985.

Eldredge N. Macroevolutionary dynamics: species, niches, and adaptive peaks. New York: McGraw-Hill; 1989.

Eldredge N. Hierarchy and macroevolution. In: Briggs DEG, Crowther PR, editors. Palaeobiology: a synthesis. Oxford: Blackwell; 1990. p. $124-129$.

Eldredge N. The pattern of evolution. New York: WH Freeman; 1999.

Eldredge N. The sloshing bucket: how the physical realm controls evolution. In: Crutchfield JP, Schuster P, editors. Evolutionary dynamics: exploring the interplay of selection, accident, neutrality, and function. Oxford: Oxford University Press; 2003. p. 3-32.

Eldredge N, Salthe SN. Hierarchy and evolution. Oxf Surv Evol Biol 1984;1:182-206.

Gaston KJ, Blackburn TM. Patterns and process in macroecology. Oxford: Blackwell; 2000.

Gilpin M, Hanski I, editors. Metapopulation dynamics: empirical and theoretical investigations. London: Academic; 1991.

Holyoak M, Leibold MA, Holt RD, editors. Metacommunities: spatial dynamics and ecological communities. Chicago: University of Chicago Press; 2005.

Ivany LC, Schopf KM, editors. New perspectives on faunal stability in the fossil record. Special issue. Palaeogeogr Palaeoclimatol Palaeoecol 1996;127:1-359.

Johnson MTJ, Stinchcombe, JR. An emerging synthesis between community ecology and evolutionary biology. Trends Ecol Evol 2007;22:250-7.

Likens GE, editor. Long-term studies in ecology: approaches and alternatives. New York: Springer; 1989.

Miller W III. Paleoecology of benthic community replacement. Lethaia 1986;19:225-31.

Miller W III. Hierarchy, individuality and paleoecosystems. In: Miller W III, editor. Paleocommunity temporal dynamics: the long-term development of multispecies assemblies. Paleontological Society 
special publication, vol 5. Ithaca: Paleontological Society; 1990. p. 31-47.

Miller W III. Hierarchical concept of reef development. Neues Jahrb Geol Paläontol Abh 1991;182:21-35.

Miller W III. Ecology of coordinated stasis. Palaeogeogr Palaeoclimatol Palaeoecol 1996;127:177-90.

Miller W III. Assembly of large ecologic systems: macroevolutionary connections. Neues Jahrb Geol Paläontol Monatsh 2004;2004:629-40.

Miller W III. The paleobiology of rarity: some new ideas. Neues Jahrb Geol Paläontol Monatsh 2005:683-93.

O'Neill RV, DeAngelis DL, Waide JB, Allen, TFH. A hierarchical concept of ecosystems. Princeton: Princeton University Press; 1986.
Polis GA, Power ME, Huxel GR, editors. Food webs at the landscape level. Chicago: University of Chicago Press; 2004.

Salthe SN. Evolving hierarchical systems: their structure and representation. New York: Columbia University Press; 1985.

Salthe SN. Development and evolution: complexity and change in biology. Cambridge: MIT; 1993.

Vrba E. Evolution, species and fossils: how does life evolve? S Afr J Sci 1980;76:61-84.

Vrba E. Environment and evolution: alternative causes of the temporal distribution of evolutionary events. S Afr J Sci 1985;81:229-36.

Vrba E. Mass turnover and heterochrony events in response to physical change. Paleobiology 2005;31(2):157-74. 